\title{
Framing the perfect strawberry: An exercise in consumer-assisted selection of fruit crops
}

\author{
Thomas A. Colquhoun ${ }^{\mathrm{a}}$, Laura A. Levin ${ }^{\mathrm{a}}$, Howard R. Moskowitz ${ }^{\mathrm{b}}$, Vance M. Whitaker ${ }^{\mathrm{c}}$, \\ David G. Clark ${ }^{\mathrm{a}, \mathrm{d}}$ and Kevin M. Folta ${ }^{\mathrm{c}, \mathrm{d}, *}$ \\ Plant Innovation Program, University of Florida, Gainesville, FL, USA \\ ${ }^{a}$ Environmental Horticultural Department, University of Florida, Gainesville, FL, USA \\ ${ }^{\mathrm{b}}$ Moskowitz Jacobs Inc., White Plains, NY, USA \\ ${ }^{\mathrm{c}}$ Horticultural Sciences Department, University of Florida, Gainesville, FL, USA \\ ${ }^{\mathrm{d}}$ Graduate Program in Plant Cellular and Molecular Biology, Gainesville, FL, USA
}

Received 5 September 2011; accepted 6 November 2011

\begin{abstract}
While hands-on, focus-group-based testing may be used to measure consumer preference, other computationally-based methods have also proven effective in testing opinions and sentiment toward a product. The IdeaMap ${ }^{\circledR}$ approach presents online, human subjects with a suite of attributes that define a given product. The subjects rate the product as these attributes change in various combinations. Upon analysis, individual attributes of the product, identified as consistently favorable or unfavorable, become apparent. In applying this methodology to strawberries, three-hundred and six subjects representing a broad cross-section of demographics from the United States were surveyed. The subjects rated perceived strawberry fruits based on appearance, texture, health benefits, flavor, point of purchase, and how they were consumed. Results from these experiments define the individual elements of a strawberry that contribute to or detract from an "ideal" strawberry experience. Furthermore, the results of this study indicate that sweetness and complex flavors are the most important attributes, while perceived health benefits had little influence on consumer preference. The point of purchase can have a strong positive or negative effect, depending on the demographic fraction. Additional analysis of these results illustrate that there is not a single, perfect strawberry. Specific likes, dislikes and preferences change with ethnicity, age, gender, urban or suburban location, education and marital status. The results from this study can help shape breeding priorities as well as provide important guidance for marketing to specific demographics in the interest of increasing strawberry consumption.
\end{abstract}

Keywords: IdeaMap, psychophysics, strawberry, Fragaria, flavor

\section{Introduction}

The cultivated strawberry (Fragaria $\times$ ananassa Duch.) is an economically valuable small fruit crop with fruit containing numerous, diverse chemical compounds that can benefit human health and nutrition. These compounds include antioxidants (especially vitamin $\mathrm{C}$ and pelargonidin-3-glucoside) vitamin B6, ellagic acid, and folic acid $[1,2]$. Multiple lines of in vitro, animal or clinical evidence indicate that strawberry-prevalent compounds have potential health benefits such as cellular anti-proliferative activities [3, 4], lipoprotein control and cardio-protective effects [5, 6], maintenance of blood glucose levels [7], and prevention of specific digestive disorders [8]. The health benefits alone provide a sound rationale to encourage greater strawberry consumption. Improved flavors and aromas would likely further increase strawberry consumption.

*Corresponding author: Kevin M. Folta, Horticultural Sciences Department, 1301 Fifield Hall, Gainesville, FL 32611, USA. Tel.: +1 352 273 4812; E-mail: kfolta@ufl.edu. 
However, traditional efforts in strawberry cultivar development have centered on supply chain traits such as yield and post-harvest quality [9]. Such breeding objectives may have deprioritized selection of traits appealing to the human senses of smell, taste, and somatosensory activation [10,11]. These sensory attributes of strawberries are difficult to manipulate because they are controlled by many different chemical and genetic constituents, which often vary due to genotype-by-environment interactions $[12,13]$. Because considerable efforts are required to improve sensory traits through genetic manipulation, it is of the utmost importance to ensure that efforts are directed toward the traits that are most likely to impact consumer purchase decisions. Therefore, a basic understanding of how consumers perceive and react to various aspects of the strawberry purchasing and consuming experience is required for maximum efficiency in selecting the best berries. We refer to this approach as "consumer assisted selection" (www.plantinnovation.org).

Evaluation of consumer preference may be performed in various ways. Indirect or near-direct quantitative measurement of human sensory response (psychophysics) is informative, yet requires carefully controlled, specialized facilities and evaluation instruments. Focus groups have been utilized extensively when assessing consumer preferences for a specific product [14]. However, this methodology often leads to data bias. For example, when an individual reads or hears (senses) a question regarding an object or experience (problem), cognition and rationalization are conserved functions that order or structure an idea and response. Thus, cognition can lead to cognitive bias whether it is founded in heuristics, social influences, and/or individual motivational factors [15].

An alternative methodology for evaluating consumer preferences relies on a modified conjoint analysis approach with relatively large populations of people. This method is a rapid and relatively inexpensive way to gauge human preference for individual terms or "word pictures" that together describe a particular product. These product elements are always presented in combinations of terms rather than singularly. This method is called rule developing experimentation (RDE) and employs a sophisticated software suite (IdeaMap ${ }^{\circledR}$ ) as a human interface and data collection system [16]. The impact of each individual product element on potential purchasing behavior as well as the emotions (general affective state) of human subjects can be objectively assessed. IdeaMap ${ }^{\circledR}$ is a software suite employed by many Fortune 500 corporations to define consumer targets using this approach (www.mji-designlab.com), and has been used in numerous peer-reviewed experimental designs [17, 18] and established books [16, 19]. Here it is applied for the first time to the strawberry, a perishable food product with extremely high economic and health value.

Through use of RDE, consumer perception toward various metrics germane to strawberry qualities, presentation, and marketing are examined. Metric preferences were compared against demographic information and general affective states. The results of this study represent the assessment from 306 individuals, measured for how strawberry-specific product elements influenced the interest and affective state toward strawberries on the market today. Interpretation of the results can provide a framework for defining "the perfect strawberry", but illustrates how the definition is really of perfect strawberr"ies" with variation between groups of subjects. These outcomes identify factors that may help prioritize strawberry breeding efforts and marketing strategies to increase a market share for enhanced strawberry products.

\section{Results}

We employed rule developing experimentation and the online IdeaMap ${ }^{\circledR}$ software suite to study US subject's interest to specific phrases rooted in specific categories of strawberry characteristics. Six strawberry characteristic categories were generated by the researchers and these categories were: berry appearance, human health and wellness, berry flavor, acquisition of berry, berry usage, and berry texture (Table 1). Within each category, word phrases (product elements) were generated with foundations of the phrases restricted by the category to which it belonged. Examples of elements used were: "Small ripe berries perfect for popping in your mouth", "So sweet ... No sugar needed", and "Berries loaded with crucial micronutrients". These elements are found in the categories berry appearance, berry flavor, and human health and wellness, respectively. Six elements for each category for a total of 36 elements were created and used for this study (Table 1). Please note, the elements and the vocabulary within each element were designed by the researchers based on anecdotal conversations with colleagues, industry members, and consumers. The respondents perceive meaning from these elements based on individual cognition and exposure to said elements and words within elements. In addition, this technology (IdeaMap) is designed to "evolve" every time it is used with a subject (i.e. generates knowledge about elements through every utilization and experimentation). 
Table 1

General experimental design of category silos and individual elements. Listed are all silos A-F (categories), berry appearance, health and wellness, berry flavor, acquisition of berry, usage of berry, and berry texture. Within each of these categories all elements are listed from A1 to F6 for a total of 36 individual elements

\begin{tabular}{|c|c|}
\hline \multicolumn{2}{|r|}{ Silo 1: CategoryA_Appearance } \\
\hline Element A1 & Large dark red berries \\
\hline Element A2 & Brilliant red berries \\
\hline Element A3 & Small ripe berries perfect for popping in your mouth \\
\hline Element A4 & Large wedge-shaped berries more than a mouthful \\
\hline Element A5 & Heart-shaped strawberries for Valentine's Day \\
\hline Element A6 & Slices of sweet red strawberries with crisp white centers \\
\hline \multicolumn{2}{|r|}{ Silo 2: CategoryB_Health and Wellness } \\
\hline Element B1 & A great source of ... Vitamin C \\
\hline Element B2 & A rich source of antioxidants \\
\hline Element B3 & No fat ... No cholesterol \\
\hline Element B4 & Berries loaded with crucial micronutrients \\
\hline Element B5 & A low-carb source of sweetness \\
\hline Element B6 & Organic berries \\
\hline \multicolumn{2}{|r|}{ Silo 3: CategoryC_Flavor } \\
\hline Element $\mathrm{C} 1$ & Berries still warm from the sunshine \\
\hline Element C2 & So sweet... No sugar needed \\
\hline Element C3 & A neutral flavor ... but complements well \\
\hline Element C4 & Large wedge-shaped berries more than a mouthful \\
\hline Element C5 & A rich, complex strawberry flavor \\
\hline Element C6 & A berry with a bit of floral essence \\
\hline \multicolumn{2}{|r|}{ Silo 4: CategoryD_Acquisition } \\
\hline Element D1 & Found at the local farmers market \\
\hline Element D2 & Picked fresh from a home garden \\
\hline Element D3 & Found at your local grocery store \\
\hline Element D4 & Found in a "big box store" \\
\hline Element D5 & Featured at a specialty produce market \\
\hline Element D6 & Purchased from a roadside stand \\
\hline \multicolumn{2}{|r|}{ Silo 5: CategoryE_Usage } \\
\hline Element E1 & Fresh sliced berries \\
\hline Element E2 & Mixed in a festive salad \\
\hline Element E3 & Slices on strawberry shortcake \\
\hline Element E4 & Hold the berry by the cap... bite it off \\
\hline Element E5 & A fresh fruit topping fit for homemade ice cream \\
\hline Element E6 & A fresh, flavorful part of everyday breakfast \\
\hline \multicolumn{2}{|r|}{ Silo 6: CategoryF_Texture } \\
\hline Element F1 & A firm berry that makes it home from the market well \\
\hline Element F2 & A crisp berry that crunches when eaten \\
\hline Element F3 & A berry that melts in your mouth \\
\hline Element F4 & A juicy berry that runs down your chin \\
\hline Element F5 & A soft berry that needs no chewing \\
\hline Element F6 & A seedless strawberry with no grit \\
\hline
\end{tabular}


A subject opened a fielding link (URL) in Windows ${ }^{\circledR}$ Internet Explorer that first showed a short welcome screen to identify the study and provide instructions for completing the study. The subject clicked the "Next" button to see three to four elements total, all from different categories (Fig. 1). The subject then read rating question one (RQ1) (Fig. 1A), which was an interest question with a nine point scale, and made an interest choice on the combination of elements present. Thus, no one element was introduced individually. Subsequent to the interest choice, the subject was asked rating question two (RQ2) on the exact same element combination (Fig. 1B), which indicated the affective state the combination of elements elicited, either: disappointed, curious, surprised, satisfied, or inspired. The subject then progressed through 48 screens, answering both rating questions. The elements were designed to appear in a random order throughout the study. After all element screens, ten demographic questions completed the study.

The study subjects represented a highly diversified population, and most bought strawberries on a regular basis and were content with their purchase (Fig. 2). A nearly equal number of males and females responded (Fig. 2A), representing an approximately equal distribution among Caucasians, African-Americans, Latinos (as), and Asians (Fig. 2C). Eighty-five percent of those surveyed were between 22 and 60 years old (Fig. 2B). In general, a subject was most likely to live in a large city or suburban area (Fig. 2D), be married (Fig. 2G), college educated at some level (Fig. 2E), and purchase strawberries approximately once per month (Fig. 2I). Over 70\% of the subjects were content with the berries they had purchased (Fig. 2J). Also noteworthy, approximately $50 \%$ of the subjects did not indicate that children lived in their household (Fig. 2F).

After all subjects $(n=306)$ had completed the study, the statistical analysis was conducted (see experimental procedures: Placket-Burman five level screening and regression analysis). The constant value (additive constant) is a calculated percentage of subjects that would answer RQ1 favorably (i.e. 7-9) if no elements were present on the screen, thus, the constant is a "baseline" and/or indicator of the subject's overall interest in the topic of the study, "the perfect strawberry". The interest values are percentages to be added to the constant and give a measure of interest or impact of individual elements compared to the constant, each other, and demographic [16].

The data were compiled into a total sample data sheet with a constant of 57 (Table 2). The elements were sorted from highest interest value to lowest interest value with all corresponding affective state values present and in the corresponding row (Table 2). For the total sample the top rated element was "So sweet... No sugar needed" with an interest value of 8 (so, $57+8=65 \%$ of the subjects are interested in strawberries if this element is present), and relatively high scores for an affective state of "satisfied" followed by "inspired". Note that the affective state "satisfied" shows the majority of the high values for most elements. This result may be a consequence of "satisfied" becoming a default affective state that the subjects chose (Table 2, column 6), and was not considered further. The

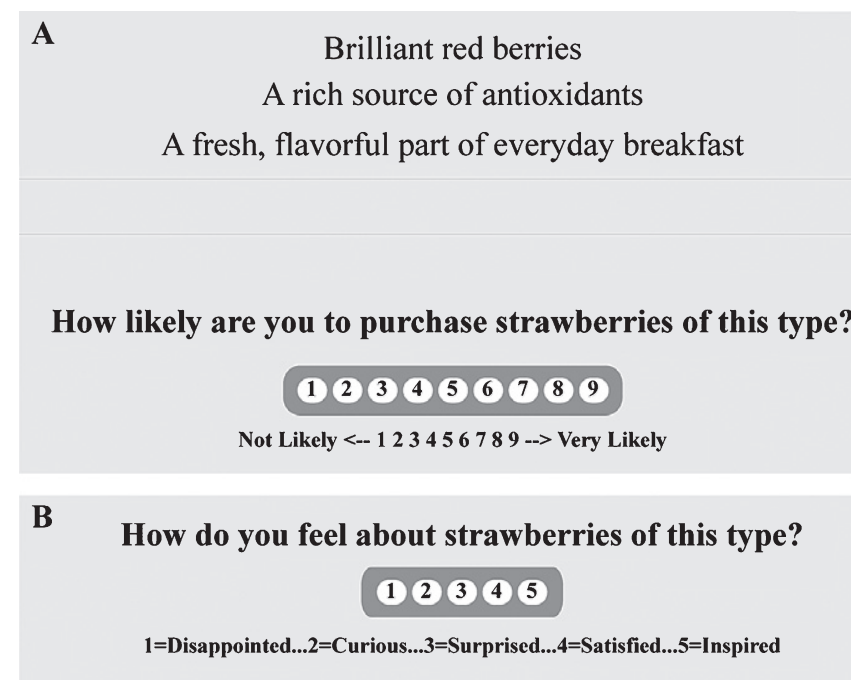

Fig. 1. Computer screen shots of Internet Explorer examples of the Perfect Strawberry IdeaMap ${ }^{\circledR}$ study. (A) An example of a screen with rating question one (interest) and a random combination of elements. (B) An example of rating question two (affective state). 
A

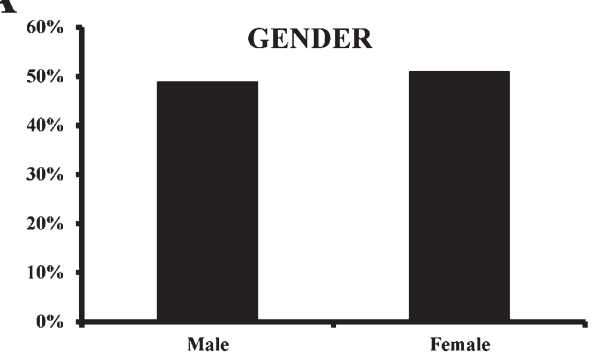

C

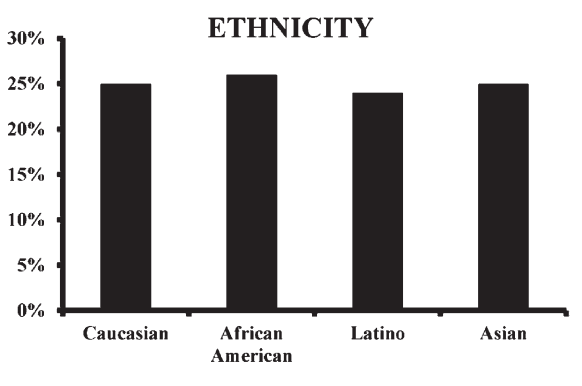

$\mathbf{E}$

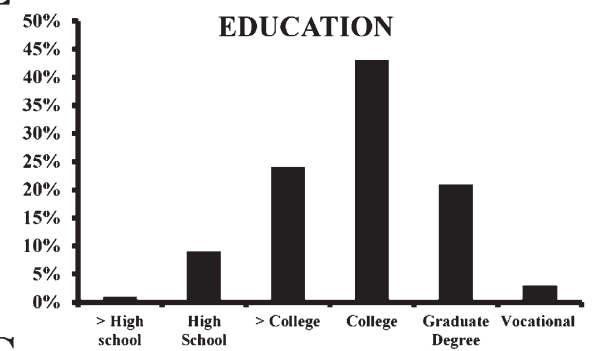

G

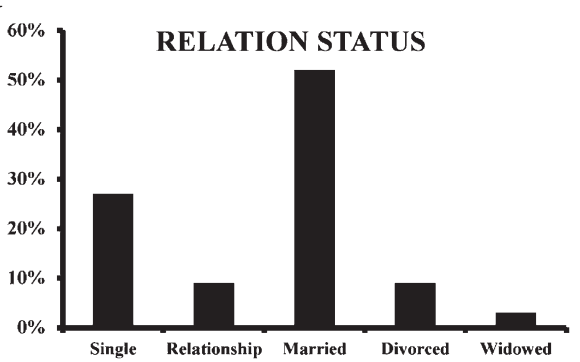

I

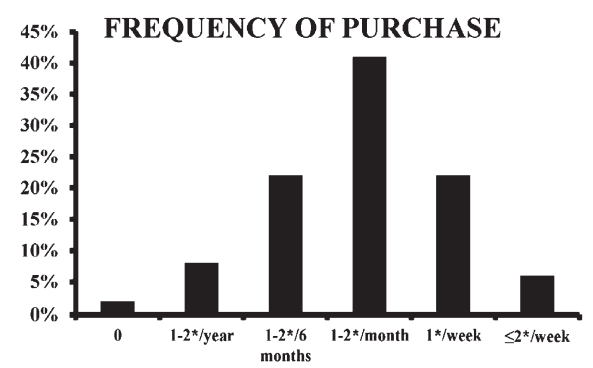

B

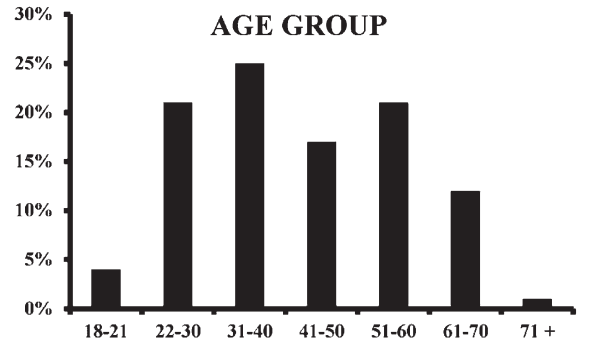

D

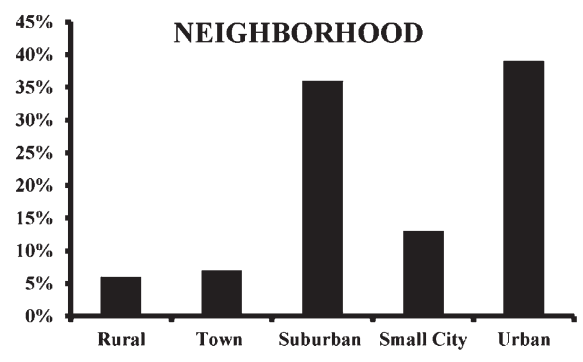

F

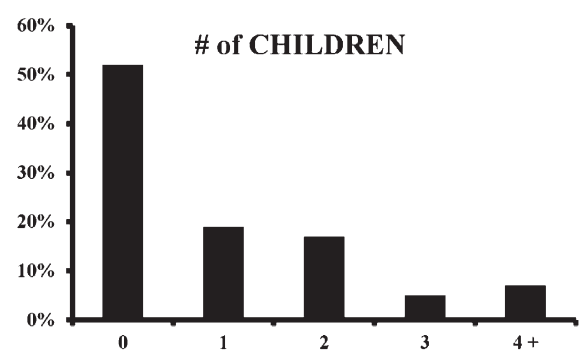

H

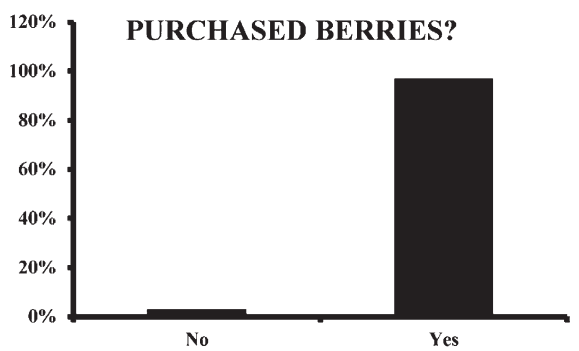

$\mathbf{J}$

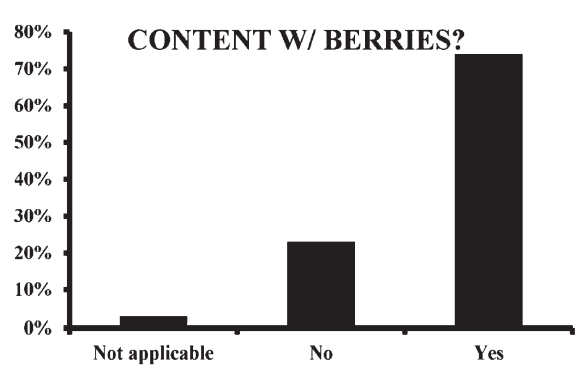

Fig. 2. Graphical representation of the demographics of 306 subjects. Shown are gender, age group, ethnicity, neighborhood of domicile, education level achieved, number of children in the household, relationships status, whether they had purchased strawberries before, the frequency of strawberry purchase, and whether they were content with the strawberry purchase. The y axis represents percent of total subjects. 
Table 2

A Topline of 306 subjects. Data shown are for both rating question 1 and 2 as denoted by the upper most horizontal. Total element interest values of all 306 subjects ranked from highest to lowest. Affective state values for disappointed, curious, surprised, satisfied, and inspired are in line with interest values. The constant is a calculated number that depicts the percentage of subjects that would respond favorably (7-9) if no elements were present, a study baseline. The interest value is a percentage that is added to the constant for percentage of subjects, which would be interested or disinterested in the respective element. The affective state values are impact values for that emotion and element

\begin{tabular}{|c|c|c|c|c|c|c|}
\hline Emotion & RQ1 & Disappointed & Curious & Surprised & Satisfied & Inspired \\
\hline Base size & 306 & 306 & 306 & 306 & 306 & 306 \\
\hline Constant & 57 & & & & & \\
\hline So sweet... No sugar needed & 8 & -1 & 1 & 3 & 13 & 9 \\
\hline Brilliant red berries & 6 & 0 & 6 & 3 & 12 & 6 \\
\hline A rich; complex strawberry flavor & 6 & 0 & 4 & 5 & 12 & 4 \\
\hline A berry that melts in your mouth & 6 & 3 & 2 & 2 & 12 & 8 \\
\hline Picked fresh from a home garden & 5 & 1 & 5 & 3 & 11 & 7 \\
\hline A fresh fruit topping fit for homemade ice cream & 4 & 1 & 2 & 1 & 13 & 9 \\
\hline Large dark red berries & 4 & 2 & 3 & 2 & 10 & 9 \\
\hline Hold the berry by the cap ... bite it off & 3 & 1 & 6 & 4 & 11 & 6 \\
\hline Large wedge-shaped berries more than a mouthful & 3 & 2 & 3 & 6 & 13 & 3 \\
\hline Found at the local farmers market & 3 & 2 & 3 & 2 & 10 & 9 \\
\hline A firm berry that makes it home from the market well & 3 & 1 & 3 & 4 & 12 & 7 \\
\hline A fresh, flavorful part of everyday breakfast & 3 & 1 & 2 & 3 & 14 & 6 \\
\hline Fresh sliced berries & 2 & 2 & 5 & 5 & 10 & 4 \\
\hline A great source of ... vitamin C & 2 & 0 & 3 & 6 & 13 & 5 \\
\hline Slices on strawberry shortcake & 2 & 1 & 2 & 7 & 9 & 6 \\
\hline A rich source of antioxidants & 2 & 0 & 2 & 6 & 12 & 7 \\
\hline A juicy berry that runs down your chin & 1 & 5 & 3 & 3 & 11 & 6 \\
\hline Berries still warm from the sunshine & 1 & 1 & 6 & 5 & 9 & 5 \\
\hline Small ripe berries perfect for popping in your mouth & 0 & 1 & 5 & 4 & 14 & 3 \\
\hline A seedless strawberry with no grit & 0 & 2 & 8 & 6 & 7 & 5 \\
\hline Found at your local grocery store & 0 & 4 & 5 & 3 & 13 & 1 \\
\hline Slices of sweet red strawberries with crisp white centers & 0 & 4 & 4 & 2 & 10 & 7 \\
\hline Featured at a specialty produce market & 0 & 1 & 6 & 2 & 12 & 5 \\
\hline No fat... No cholesterol & -1 & 0 & 6 & 5 & 8 & 6 \\
\hline Organic berries & -1 & 3 & 4 & 8 & 7 & 5 \\
\hline Purchased from a roadside stand & -1 & 4 & 5 & 3 & 8 & 7 \\
\hline Berries loaded with crucial micronutrients & -3 & 1 & 4 & 8 & 10 & 4 \\
\hline A low-carb source of sweetness & -3 & 1 & 7 & 7 & 8 & 3 \\
\hline Mixed in a festive salad & -4 & 3 & 4 & 9 & 8 & 2 \\
\hline Heart-shaped strawberries for Valentine's Day & -4 & 5 & 6 & 5 & 7 & 5 \\
\hline A berry with a bit of floral essence & -5 & 2 & 8 & 7 & 6 & 2 \\
\hline A crisp, tart berry that wakes the taste buds & -5 & 7 & 7 & 7 & 2 & 4 \\
\hline A crisp berry that crunches when eaten & -6 & 3 & 9 & 4 & 8 & 2 \\
\hline A soft berry that needs no chewing & -7 & 7 & 10 & 6 & 3 & 1 \\
\hline Found in a "big box store" & -8 & 5 & 8 & 3 & 11 & 1 \\
\hline A neutral flavor ... but compliments well & -9 & 9 & 5 & 5 & 7 & 0 \\
\hline
\end{tabular}

lowest rated element for the total sample was "A neutral flavor ... but complements well" with an interest value of -9 and the highest relative score for an affective state of "disappointed".

Only the top two and bottom two elements will be shown in the tables for spatial considerations (the complete data set is available at www.plantinnovation.org/perfectstrawberry). Separation of male subjects from female subjects 
illustrated that the males were generally less interested in strawberries (male constant 44, female constant 69), and the females were less interested by the elements used in this study than they were interested by the elements (high intresest value for male $=11$ and low $=-4$, differential of 15 ; female high $=6$ and low $=-13$, differential of 19) (Table 3). Highest interest value for both genders was for the element "So sweet... No sugar needed"; and the lowest value was for "A neutral flavor... but complements well". The next element was divergent between the gender split. A berry acquisition element of elevated (9) interest to males was, "Picked fresh from a home garden", while a berry flavor element of interest to females was, "A rich, complex strawberry flavor". Female subjects had a strong (-12) disinterest for "Found in a "big box store" " (Table 3).

The data set was also separated based on age groups (Table 4). The vast majority (97\%) of subjects were between the ages of 22 and 70, and based on the construction of the demographic question the age groups were: 22-30, 31-40, 41-50, 51-60, and 61-70. The 22-30 age group had a base size of 63 subjects and resulted in a relatively high constant with very high numbers on the disinterest spectrum $(-19)$ for again "A neutral flavor ... but complements well" (Table 4). The highest interest value for this demographic was for "Found at the local farmers market" with a value of eight. Subjects between 31 and 50 years old showed stronger interests to some elements while being less negative toward those elements they found unfavorable, relative to other age groups. The more advanced age demographics rate the "negative" elements more strongly, with age.

Table 5 analyzes the data by ethnicity. There were approximately equal numbers of participants in the four groups studied. The data indicate strong interests or disinterests based on ethnicity. While all groups demonstrated relatively strong disinterest in the elements they disliked, Caucasian subjects were especially disenchanted with elements that described a tart or neutral flavor (Table 5). Conversely, Latino/a subjects showed a higher interest level in positive attributes of the berry; these associated with flavor: primarily complexity and sweetness. African-American subjects responded most positively to visual qualities and the general berry experience with "brilliant red berries" and "hold the berry by the cap ... bite it off" being the most positive (Table 5). The same group responded negatively to "found in a "big box store", whereas other demographics did not demonstrate such strong disinterest about elements of point of purchase. Asian subjects rated the elements associated with purchase highly. They also valued festivity-centric use of berries (in this case Valentine's Day) especially low, a unique outcome among ethnic groups (Table 5).

Strawberry consumers from suburban and urban locales exhibited distinct classes of berry perception. Suburban likes and dislikes centered on sensory experiences, as sweetness and "melt in your mouth" were highly favorable (Table 6). Crispiness and non-committal flavors were strongly negative. Urban consumers also showed strong interest in positive sensory attributes, noting that "rich, complex flavors" and sweetness were the most favorable qualities.

Table 3

Gender comparison. The total sample data was separated by gender. The base sizes and constants for each subject population are shown under the general heading. Also, illustrated are the top two and bottom two elements ranked by interest values. Note the relatively high positive value for male top elements and the very low value for female bottom elements

\begin{tabular}{lc}
\hline Gender & Male \\
Base size & 151 \\
Constant & 44 \\
So sweet .. No sugar needed & 11 \\
Picked fresh from a home garden & 9 \\
A soft berry that needs no chewing & -4 \\
A neutral flavor ... but complements well & -4 \\
Gender & Female \\
Base size & 155 \\
Constant & 69 \\
So sweet ... No sugar needed & 6 \\
A rich, complex strawberry flavor & 5 \\
Found in a "big box store" & -12 \\
A neutral flavor ... but complements well & -13 \\
\hline
\end{tabular}


Table 4

Age group comparison. The total sample data was separated by age group and listed first by youngest first. The base sizes and constants for each subject population are shown under the general heading. Illustrated are the top two and bottom two elements ranked by interest values

\begin{tabular}{|c|c|}
\hline Age (years) & $22-30$ \\
\hline Base size & 63 \\
\hline Constant & 62 \\
\hline Found at the local farmers market & 8 \\
\hline Picked fresh from a home garden & 7 \\
\hline A crisp, tart berry that wakes the taste buds & -10 \\
\hline A neutral flavor ... but complements well & -19 \\
\hline Age (years) & $31-40$ \\
\hline Base size & 76 \\
\hline Constant & 40 \\
\hline A rich, complex strawberry flavor & 16 \\
\hline So sweet ... No sugar needed & 15 \\
\hline Found in a "big box store" & -6 \\
\hline Mixed in a festive salad & -7 \\
\hline Age (years) & $41-50$ \\
\hline Base size & 51 \\
\hline Constant & 55 \\
\hline A fresh fruit topping fit for homemade ice cream & 12 \\
\hline So sweet... No sugar needed & 10 \\
\hline Found in a "big box store" & -8 \\
\hline A low-carb source of sweetness & -11 \\
\hline Age (years) & $51-60$ \\
\hline Base size & 65 \\
\hline Constant & 62 \\
\hline Fresh sliced berries & 11 \\
\hline Slices on strawberry shortcake & 10 \\
\hline Organic berries & -12 \\
\hline A soft berry that needs no chewing & -15 \\
\hline Age (years) & $61-70$ \\
\hline Base size & 37 \\
\hline Constant & 69 \\
\hline A berry that melts in your mouth & 9 \\
\hline Slices on strawberry shortcake & 7 \\
\hline A crisp, tart berry that wakes the taste buds & -16 \\
\hline A crisp berry that crunches when eaten & -21 \\
\hline
\end{tabular}

However, their most intense negative perceptions followed point of purchase, where "big box store" was of strong disinterest. The idea of using strawberries for Valentine's Day also did not resonate with urban consumers (Table 6).

Education demographics can also segment the subjects. College graduates reacted most strongly to sensory attributes of strawberries, as both their most extreme likes and dislikes were based on flavors (Table 7). This group contrasted against those that have fewer than two years of college that reacted positively to "Picked fresh from the home garden" and "brilliant red berries", while "big box store" berries or soft berries were substantially negative. Those representing the Professional (M.D., Ph.D., etc.) category gave positive responses to sensory qualities flavor and "melts in your mouth", yet responded negatively to crisp berries and the heart-shaped berry for Valentine's Day (Table 7). 
Table 5

Ethnicity comparison. The total sample data was separated by ethnicity and listed as the choices appeared in the demographic questions section of the study. The base sizes and constants for each subject population are shown under the general heading. Illustrated are the top two and bottom two elements ranked by interest values

\begin{tabular}{|c|c|}
\hline Ethnicity & Caucasian \\
\hline Base size & 78 \\
\hline Constant & 64 \\
\hline So sweet... No sugar needed & 9 \\
\hline Picked fresh from a home garden & 9 \\
\hline A crisp, tart berry that wakes the taste buds & -19 \\
\hline A neutral flavor ... but complements well & -24 \\
\hline Ethnicity & African-American \\
\hline Base size & 80 \\
\hline Constant & 63 \\
\hline Brilliant red berries & 8 \\
\hline Hold the berry by the cap... bite it off & 8 \\
\hline A crisp berry that crunches when eaten & -13 \\
\hline Found in a "big box store" & -14 \\
\hline Ethnicity & Hispanic/Latino \\
\hline Base size & 72 \\
\hline Constant & 42 \\
\hline A rich, complex strawberry flavor & 16 \\
\hline So sweet... No sugar needed & 16 \\
\hline Mixed in a festive salad & -5 \\
\hline A soft berry that needs no chewing & -10 \\
\hline Ethnicity & Asian \\
\hline Base size & 76 \\
\hline Constant & 56 \\
\hline A firm berry that makes it home from the market well & 9 \\
\hline Found at your local grocery store & 8 \\
\hline A neutral flavor ... but complements well & -7 \\
\hline Heart-shaped strawberries for Valentine's Day & -11 \\
\hline
\end{tabular}

The preferences of married and unmarried subjects were also compared (Table 8). Here the two groups responded positively to different elements that are based on sensory qualities. Complicated flavors were highly favorable with single subjects, whereas sweetness was most favorable among married subjects. Single subjects responded most negatively to the "neutral flavor" element, whereas the married subjects found "big box store" berries to be unfavorable (Table 8). Married subjects also noted "a low-carb source of sweetness" as negative. Married subjects generally did not have the amplitude of liking and disliking that was exhibited by single subjects.

When frequency of purchase was analyzed several consumer groups emerged. Consumers that rarely purchased strawberries ( $\geq 1-2$ times per 6 months) show strong disinterests against more elements of the strawberry experience, compared to those that purchased them on a more regular basis (Table 9). Conversely, consumers that buy strawberries most frequently resulted in positive attributes more positively in magnitude. Among these was a desire for sweet complex flavor over point of purchase or how it was presented. Subjects in the study that did not purchase strawberries often were most excited by color or presentation, not flavor. The same demographic also resulted with "big box store" strawberries very low in favor, which indicates a negative association (Table 9).

One final way the total data set was examined was with cluster analysis. We used K-Clustering [20], which was carried out by the software SYSTAT 13 (www.systat.com, Chicago, IL). K-Clustering simply identified the best way to divide objects (data points) into " $K$ " (where " $K$ " is a set value) different segments. We set " $K$ " to 3 (Table 10) and 


\section{Table 6}

Location of residence comparison. The total sample data was separated by living location (neighborhood) and listed first by suburban followed by urban environments. The base sizes and constants for each subject population are shown under the general heading. Illustrated are the top two and bottom two elements ranked by interest values

\begin{tabular}{lc}
\hline Residence & Suburban \\
Base size & 110 \\
Constant & 64 \\
So sweet ... No sugar needed & 12 \\
A berry that melts in your mouth & 7 \\
A crisp berry that crunches when eaten & -13 \\
A neutral flavor ... but complements well & -16 \\
Residence & Urban \\
Base size & 120 \\
Constant & 46 \\
A rich, complex strawberry flavor & 10 \\
So sweet ... No sugar needed & 10 \\
Heart-shaped berries for Valentine's Day & -4 \\
Found in a "big box store" & -11 \\
\hline
\end{tabular}

Table 7

Education comparison. The total sample data was separated by education level and listed first by less than two years of college experience. The base sizes and constants for each subject population are shown under the general heading. Illustrated are the top two and bottom two elements ranked by interest values. Note, the "professional" heading indicates graduate school or post graduate school

\begin{tabular}{lc}
\hline Education & College $>2$ yrs \\
Base size & 73 \\
Constant & 78 \\
Picked fresh from a home garden & 7 \\
Brilliant red berries & 6 \\
Found in a "big box store" & -16 \\
A soft berry that needs no chewing & -24 \\
Education & College \\
Base size & 131 \\
Constant & 47 \\
So sweet ... No sugar needed & 11 \\
A fresh fruit topping fit for homemade ice cream & 11 \\
A crisp berry that crunches when eaten & -8 \\
A neutral flavor... but complements well & -10 \\
Education & Professional \\
Base size & 63 \\
Constant & 58 \\
A rich, complex strawberry flavor & 10 \\
A berry that melts in your mouth & 8 \\
A crisp berry that crunches when eaten & -8 \\
Heart-shaped strawberries for Valentine's Day & -12 \\
\hline
\end{tabular}


Table 8

Relationship status comparison. The total sample data was separated by relationship status and listed first by single first followed by married. The base sizes and constants for each subject population are shown under the general heading. Illustrated are the top two and bottom two elements ranked by interest values

\begin{tabular}{lc}
\hline Relationship & Single \\
Base size & 83 \\
Constant & 47 \\
A rich, complex strawberry flavor & 13 \\
A fresh fruit topping fit for homemade ice cream & 11 \\
Found in a "big box store" & -6 \\
A neutral flavor ... but complements well & -13 \\
Relationship & Married \\
Base size & 159 \\
Constant & 60 \\
So sweet ... No sugar needed & 11 \\
Brilliant red berries & 9 \\
Found in a "big box store” & -8 \\
A low-carb source of sweetness & -8 \\
\hline
\end{tabular}

in a separate analysis to 5 in order to expand the groups as much as numerically feasible (Table 11). The first analysis of three segments resulted in a segment having a base size of 114 with a constant of 71 (segment 1), a segment consisting of 147 subjects with a constant of 45 (segment 2), and a segment of 45 subjects with a constant of 58 (Table 10). Segment 1 resulted with top elements of "So sweet... No sugar needed" (13) and "A berry that melts in your mouth" (12), and bottom elements "Mixed in a festive salad" $(-15)$ and "Found in a 'big box store' " (-23) (Table 10). The most disinterested element at a value of -24 was also the most curious to segment 1 , and both top elements showed high numbers for the affective state of "inspired". We gave segment 1 the descriptor, "so sweet it melts". Segment 2 rated elements highly dealing with “... fresh fruit..." and "Picked fresh ...", so we named this segment "freshies". This segment was most disinterested by "A soft berry ..." and "A neutral flavor..." with the latter achieving the highest affective state value as disappointed. The third segment termed "the connoisseur" had elements focused on a "... specialty produce market" and "Organic berries" as the most favorable (Table 10). The connoisseur segment's nonfavorable elements $(-20)$ again achieved the highest affective state value as "curious" (much like segment 1), and a high value for the affective state of "surprised". Together the cluster analysis clearly illustrated three segments of the subject population with different elements and affective states that may depict the foundation of the individual segment of strawberry consumers.

When the data was segmented further into five K-clusters (Table 11), it is apparent that segments 1 and 2 from the previous segment analysis (Table 10) could be reduced further, and still retain reasonable numbers of subjects for all five new segments (note segment 5 is conserved from segment 3 of Table 10). Again, all five segments differed in the top most favorable elements and in the bottom most favorable elements. The headings of "messy sweet inspiration", "healthy treats that satisfy and inspire", "satisfied with big red", "a fresh bite", and "the connoisseur" were all meant to summarize the individual segments elemental interests and encompass some affective states, which appeared to explain the elements favor (Table 11). As a result of the segmentation or cluster analysis, the subjects are clearly divided into discernible "groups" of consumers that have very specific interests in particular elements that elicit a specific affective state (Tables 10 and 11).

\section{Discussion}

In the quest to produce the perfect strawberry it may be best to step aside from our preconceptions as scientists that are based on perceived industry needs and turn to the consumer. Analysis of consumer sentiments toward various attributes of strawberry fruit quality, presentation and purchase can frame a target to guide breeding and 
Table 9

Strawberry purchase frequency comparison. The total sample data was separated by frequency of strawberry purchase and listed first by one or two times a year followed by one to two times per six months, one to two times per month, and finally one time per week. The base sizes and constants for each subject population are shown under the general heading. Illustrated are the top two and bottom two elements ranked by interest values

\begin{tabular}{|c|c|}
\hline Frequency of strawberry purchase & $1-2 * /$ year \\
\hline Base size & 25 \\
\hline Constant & 39 \\
\hline Brilliant red berries & 14 \\
\hline Fresh sliced berries & 9 \\
\hline A soft berry that needs no chewing & -13 \\
\hline Found in a "big box store" & -14 \\
\hline Frequency & $1-2 * / 6$ month \\
\hline Base size & 68 \\
\hline Constant & 62 \\
\hline A berry that melts in your mouth & 11 \\
\hline Fresh sliced berries & 9 \\
\hline A crisp, tart berry that wakes the taste buds & -12 \\
\hline A neutral flavor ... but complements well & -16 \\
\hline Frequency & $1-2 * /$ month \\
\hline Base size & 124 \\
\hline Constant & 67 \\
\hline So sweet... No sugar needed & 6 \\
\hline Found at the local farmers market & 5 \\
\hline A soft berry that needs no chewing & -9 \\
\hline A crisp berry that crunches when eaten & -9 \\
\hline Frequency & $1 * /$ week \\
\hline Base size & 66 \\
\hline Constant & 45 \\
\hline So sweet... No sugar needed & 16 \\
\hline A rich, complex strawberry flavor & 14 \\
\hline Found in a "big box store" & -5 \\
\hline A neutral flavor ... but complements well & -9 \\
\hline
\end{tabular}

selection efforts, while at the same time informing more potent marketing strategies to encourage greater sales. Simultaneously, the same data provide important demographic information that opens the opportunity to selective targeting of individual sub-populations for advertising and information campaigns, as well as the possibility of new cultivars that are segment specific. The implementation of the IdeaMap ${ }^{\circledR}$ approach is an effective complement to direct consumer tests with targeted fruit products.

The population surveyed was ideal for this study. The subjects represented the age group that typically makes food-purchase decisions, and was split almost equally in terms of gender and four ethnicities. The subjects purchased strawberries on a regular basis, the majority making weekly to monthly purchases. These numbers were comparable with those presented by the California Strawberry Commission report showing that when strawberries are purchased by consumers on a regular basis, there is substantial opportunity to increase sales (www.calstrawberry.com, strawberry consumer purchase trends). Improvement of the commercial strawberry coupled to more effective marketing strategies would likely be an effective means to increase strawberry consumption. Thus, the need to develop a concept of the optimal product and avenues to best reach the consumer justified the need for this study.

The interpretations of the data fall into two major categories for each population tested. First, there was a clear indication that various segments of subjects demonstrated significant amplitude effects in their degree of liking or 
Table 10

Total sample clustered into three segments. K-cluster analysis to three total clusters results in the three best fit segments shown. The top two and bottom two elements are illustrated with emotion values to the right. The heading of each segment is a familiar term for each segment derived by the researchers

\begin{tabular}{|c|c|c|c|c|c|c|}
\hline So sweet it melts & Segment 1 & Disappointed & Curious & Surprised & Satisfied & Inspired \\
\hline Base size & 114 & 114 & 114 & 114 & 114 & 114 \\
\hline Constant & 71 & & & & & \\
\hline So sweet ... No sugar needed & 7 & 0 & -5 & 5 & 14 & 13 \\
\hline A berry that melts in your mouth & 6 & 1 & 0 & 2 & 12 & 11 \\
\hline Mixed in a festive salad & -16 & 4 & 7 & 8 & 10 & -3 \\
\hline Found in a "big box store" & -24 & 8 & 13 & 3 & 6 & -3 \\
\hline Freshies & Segment 2 & Disappointed & Curious & Surprised & Satisfied & Inspired \\
\hline Base size & 147 & 147 & 147 & 147 & 147 & 147 \\
\hline Constant & 45 & & & & & \\
\hline A fresh fruit topping fit for homemade ice cream & 15 & -1 & -3 & 3 & 17 & 11 \\
\hline Picked fresh from a home garden & 14 & 1 & 2 & 4 & 11 & 9 \\
\hline A soft berry that needs no chewing & -10 & 9 & 9 & 7 & 4 & -2 \\
\hline A neutral flavor ... but complements well & -13 & 11 & 6 & 4 & 4 & 0 \\
\hline The connoisseur & Segment 3 & Disappointed & Curious & Surprised & Satisfied & Inspired \\
\hline Base size & 45 & 45 & 45 & 45 & 45 & 45 \\
\hline Constant & 58 & & & & & \\
\hline Featured at a specialty produce market & 12 & -5 & 3 & -2 & 19 & 13 \\
\hline Organic berries & 11 & -1 & 7 & 5 & 3 & 10 \\
\hline A neutral flavor $\ldots$ but complements well & -20 & 7 & 3 & 13 & 8 & -8 \\
\hline A crisp berry that crunches when eaten & -20 & 5 & 12 & 8 & 5 & -3 \\
\hline
\end{tabular}

disliking for various strawberry attributes. For instance, the interest data in Table 3 show that while both males and females have discrete elements to which they react strongly, their reactions are in different areas. Female subject's exhibit strong negative interest values, whereas men's appreciation for various strawberry attributes are quite strong. The amplitude of interest-disinterest is important because it quantifies the degree of response to a given element.

The second major class of interpretations comes from analysis of the favorable or disliked elements themselves, and how they relate to different demographic segments. Clear preferences were found for individual groups of subjects that reflected their gender, age, ethnicity or other population segment. These specific elements are important to consider in the design of the perfect strawberry, how it is marketed, and possibly how specific populations are targeted to increase strawberry consumption.

Table 2 illustrates subject's aggregate interest value for individual elements sorted most positive to least. Certainly, sweetness has the strongest influence on flavor perception (Table 2). This is consistent with taste panel studies showing that sweetness describes a large portion of the variation in flavor ratings and helps lend confidence in the results [21]. However, this study shows that a mildly sweet but simple flavor may not be highly regarded since a "neutral" flavor was the lowest rated element, lower even than "a crisp, tart berry that wakes the taste buds" (Table 2). Flavor characteristics elicit the greatest positive response for those consumers that purchase more frequently, while those that purchase less frequently are more positively influenced by color, texture, and usage attributes (Table 9). Yet, for those people that purchase strawberries only once or twice in a six month period, strawberries with tart or neutral flavors are viewed quite negatively. It is possible that by enhancing the flavor attributes of strawberries, flavor could become a more influential positive attribute for some consumers and result in more frequent purchasing behavior.

Consumers responded positively to a "berry that melts in your mouth" while interest in elements containing the word "crisp" was very low (Tables 2, 4, 6, 7, 9, and 10). However, care must be taken in interpretation of these results in regards to texture since a "soft berry that needs no chewing" showed a low interest value (Table 2), while a "firm berry that makes it home from the market well" had positive values (Tables 2 and 5). A firm (but not crisp) berry 
Table 11

Total sample clustered into five segments. K-cluster analysis to five total clusters results in the five best fit segments shown. The top two and bottom two elements are illustrated with emotion values to the right. The heading of each segment is a familiar term for each segment derived by the researchers

\begin{tabular}{|c|c|c|c|c|c|c|}
\hline Messy sweet inspiration & Segment 1 & Disappointed & Curious & Surprised & Satisfied & Inspired \\
\hline Base size & 48 & 48 & 48 & 48 & 48 & 48 \\
\hline Constant & 69 & & & & & \\
\hline A juicy berry that runs down your chin & 21 & 2 & 2 & 1 & 10 & 12 \\
\hline So sweet ... No sugar needed & 17 & -4 & -1 & 9 & 6 & 17 \\
\hline Fresh sliced berries & -19 & 5 & 8 & 9 & 6 & -1 \\
\hline Mixed in a festive salad & -26 & 5 & 12 & 10 & 4 & -5 \\
\hline Healthy treats that satisfy and inspire & Segment 2 & Disappointed & Curious & Surprised & Satisfied & Inspired \\
\hline Base size & 73 & 73 & 73 & 73 & 73 & 73 \\
\hline Constant & 37 & & & & & \\
\hline A great source of ... vitamin $\mathrm{C}$ & 21 & -3 & -3 & 0 & 24 & 9 \\
\hline A fresh fruit topping fit for homemade ice cream & 21 & -1 & -8 & 8 & 12 & 16 \\
\hline A juicy berry that runs down your chin & -17 & 9 & 6 & 1 & 13 & -1 \\
\hline A soft berry that needs no chewing & -22 & 17 & 9 & 12 & -2 & -8 \\
\hline Satisfied with big red & Segment 3 & Disappointed & Curious & Surprised & Satisfied & Inspired \\
\hline Base Size & 66 & 66 & 66 & 66 & 66 & 66 \\
\hline Constant & 72 & & & & & \\
\hline Large dark red berries & 18 & 2 & -1 & 0 & 13 & 14 \\
\hline Brilliant red berries & 12 & -3 & 4 & 3 & 13 & 8 \\
\hline Featured at a specialty produce market & -26 & 6 & 12 & 4 & 3 & -1 \\
\hline Found in a "big box store" & -32 & 8 & 18 & 5 & 3 & -7 \\
\hline A fresh bite & Segment 4 & Disappointed & Curious & Surprised & Satisfied & Inspired \\
\hline Base size & 74 & 74 & 74 & 74 & 74 & 74 \\
\hline Constant & 53 & & & & & \\
\hline Picked fresh from a home garden & 20 & -2 & 1 & 2 & 13 & 12 \\
\hline Hold the berry by the cap ... bite it off & 18 & -1 & 3 & 1 & 14 & 11 \\
\hline A crisp, tart berry that wakes the taste buds & -17 & 13 & 13 & 12 & -10 & 0 \\
\hline A neutral flavor ... but complements well & -25 & 13 & 8 & 8 & -4 & -2 \\
\hline The connoisseur & Segment 5 & Disappointed & Curious & Surprised & Satisfied & Inspired \\
\hline Base Size & 45 & 45 & 45 & 45 & 45 & 45 \\
\hline Constant & 58 & & & & & \\
\hline Featured at a specialty produce market & 12 & -5 & 3 & -2 & 19 & 13 \\
\hline Organic berries & 11 & -1 & 7 & 5 & 3 & 10 \\
\hline A neutral flavor ... but complements well & -20 & 7 & 3 & 13 & 8 & -8 \\
\hline A crisp berry that crunches when eaten & -20 & 5 & 12 & 8 & 5 & -3 \\
\hline
\end{tabular}

that has a smooth internal texture would be expected to be pleasing to the majority of consumers according to these results. It also appears that breeders may be justified in continuing to focus on gains in fruit size, since elements containing the word "large" elicited positive responses while "small ripe berries perfect for popping in your mouth" elicited neither a positive nor a negative response (Table 2).

While males and females respond robustly to only a few survey elements, they respond quite differently (Table 3). Females exhibit strong negative perceptions and relatively weak positive ones. Conversely, the survey attributes that males found attractive rated highly favorable, while their negative feelings were not as strong. These results may be interpreted to conclude that it is easier to lose a women's interest in the product than a man's, and that men are more easily motivated by the aspects they appreciate than women. 
Comparison of elements within the different age groups showed that few trends exist between subjects of varying age (Table 4). The trend for highly liked strawberry attributes shifted with age from where berries are purchased, to how they taste, to how they are prepared. Young adults (22-30 years) rate berries from "the local farmers market" and "from the home garden" to be most favorable. Thirty-one to fifty year olds show high preference for complex, sweet flavors. At the same time the forty-one to seventy year olds were not influenced by flavor and point of purchase and emphasize presentation and texture as most important with the highest interest values relating to "sliced berries", toppings, or "melt in your mouth" elements. The oldest demographic also disliked crisp berries, potentially because they conceptually clash with memories of soft, fresh berries from yesteryear that are the foundation of their expectations.

Another unexpected outcome was that throughout the survey there was little subject interest in the health attributes of strawberries (Table 2). The only exception was the segment that favored the element, "A great source of Vitamin C", important as a berry attribute (Table 11). One interpretation is that while healthful qualities of fresh small fruits are important, they are a low priority compared to the sensory attributes that make a strawberry appealing. In other words, a promise of positive health effects would not elevate consumer perception of a mediocre berry quality in this study. At the same time, health benefits were not generally perceived negatively. The only exceptions are in married individuals and subjects between 41-50 years of age that considered "a low-carb sources of sweetness" to be a negative aspect of the strawberry presented (Tables 4 and 8). Also, "No fat ... no cholesterol" was perceived negatively by infrequent strawberry purchasers, whereas the term was neutral among all others (Table 9). Alternatively, this may indicate that specificity in element wordage may be needed to evaluate nutritive qualities of strawberries for this group of consumers.

Some of the limitations of the study lie in that the subjects were all from the U.S. While cultivar names are not used in commercial marketing in the United States, cultivar names are often included on packaging in European markets and are individually promoted. This allows marketers in certain segments of Europe to target cultivars to market niches. However, strawberry growers in North America also have the ability to target different segments of consumers by preferentially shipping fruit to wholesale buyers and retail outlets of different types and locales; they just have not capitalized on the target marketing yet.

The vast majority of subjects were generally content with their strawberry purchases (Fig. 2). This outcome is positive in that those participating in the survey are familiar with the product and are likely to have purchased it on a "regular" basis. Thus, their perceptions are based in a general liking of strawberries, and the results of this study suggest a targeting for a better product to increase market share, not conversion of product non-users.

The power of this type of study is that the data can explain what the consumer is truly interested in about a strawberry and how they want the strawberry presented. However, the consumer demands must be tempered against genetics and environment, by logistics and practicality. Elite germplasm must meet an entire series of criteria before the consumer ever samples the fruit. Resistance to disease, yield, firmness, and fruit size are important considerations for the ideotypical perfect strawberry long before it gets to the table. These considerations are always in play, and using consumer survey tools simply defines the best possible target to work for within this limitation structure.

An IdeaMap ${ }^{\circledR}$ approach provides information about what attributes of the strawberry experience are viewed positively and negatively by consumers. The ultimate synthesis reveals that the best consensus strawberry for the consumers tested in this study; is sweet with complex flavors. The color and shape descriptions used here are not as critical to this group of consumers. A crisp texture or neutral flavor is not desirable. The point of purchase is influential among certain sections of the population, whereas others have no preference. Frequent purchasers relish the positive attributes and infrequent purchasers emphasize the negative attributes. Most of all, the study reveals that there is not likely one perfect strawberry, but rather, perfect strawberries. Different population segments react more strongly to specific attributes of the strawberry experience, suggesting that a one-size-fits-all approach to breeding and marketing may be shortsighted. This study provides valuable insight into what consumers really covet, providing empirical guidance toward the breeding and eventual marketing of the perfect strawberry.

\section{Experimental procedures}

To test consumer's preferences and perceptions of a perishable food product, strawberries, we employed a welldocumented rule developing experimentation (RDE) methodology [16]. RDE was developed by Moskowitz Jacobs 
Inc. (www.mji-designlab.com: White Plains, New York) in cooperation with the Wharton School of Business at the University of Pennsylvania (www.wharton.upenn.edu). From a statistical prospective, RDE utilizes modified conjoint analysis methods [22] to assay a combination of independent variables in a way that allows each independent variable to affect another, which would not be observable through a traditional one-at-a-time approach [23].

The subject of our experimentation or "target product" was a strawberry, and we named our study "The Perfect Strawberry". To begin, we dissected a "strawberry" into six feature categories or "silos": 1) Appearance, 2) Texture, 3) Flavor, 4) Usage, 5) Health and Wellness, 6) Acquisition. Next, we devised "elements" or word pictures that pertained to each feature category, much like: 1) Appearance - A1) Large dark red berries. All Silos and elements are represented in Table 1. These categories and elements were then uploaded to an online software suite called IdeaMap $^{\circledR}$ at www.ideamap.net, which is maintained by Moskowitz Jacobs Inc. In addition, we constructed a study welcome screen, two rating questions, and 10 demographic questions all with similar formatting. The organization of the online study was as follows: welcome screen, 48 screens of random element combinations with both rating questions asked (Fig. 1), 10 demographic question screens, and a "thank you" screen.

Panel Direct Online (www.paneldirectonline.com), a division of Focus Forward, LLC (www.focusfwd.com), was employed to recruit study subjects with three screening questions because we wanted a certain base demographic in this study. The subject screening questions (s) were as follows: s1) please specify your gender (we wanted $\sim 50 / 50$ split between male and female), s2) for demographic purposes only, which best describes your ethnic background (we wanted $\sim 25 / 25 / 25 / 25$ split between Caucasian, African American, Latino, and Asian), s3) which age group do you belong to (we wanted a 33.3/33.3/33.3 split between 18-34, 35-54, and 55 and over). A total of 364 subjects logged into The Perfect Strawberry study, and 306 subjects completed the study.

The RDE experimental design and mathematical analysis used to generate and evaluate the data for this study has been well described in both peer-reviewed journal articles and published books [16-18]. In brief, this methodology comprises several steps. 1) Silo and element construction as described previously. 2) Experimental design, which constitutes 48 combinations of 36 elements where each element appears independently of every other element at an equal number of times in randomized combinations. Additionally, each subject is subjected to permutated experimental designs so to ensure each subject is presented with a unique set of combinations. 3) Field execution as described earlier with the help of Panel Direct Online and the software suite IdeaMap ${ }^{\circledR}$. 4) Utilizing a Plackett-Burman five level screening design [24], this provides an efficient method for combining elements (independent variable) [17]. E.g. the combinations of elements are coded as a set of 1 's and 0 's ( $1=$ presence of element; $0=$ absence of element). Every test concept comprises a row, and every column is an element. The last column is the rating (dependent variable), which can either be the actual numerical scale assigned by the subject (i.e. the anchored 1-9 rating scale shown in Fig. 1), or a recoded scale (such as a binary value) to denote that the subject accepts of or rejects the concept. 5) Regression modeling (dummy variable) of the data from the Plackett-Burman screening design. Note that the original experimental design ensures that all 36 elements are statistically independent of each other. The model is simple and an obvious additive equation of the form:

$$
\text { Rating }=\mathrm{k}_{0}+\mathrm{k}_{1}+\mathrm{k}_{2} \ldots \mathrm{k}_{36}
$$

where $\mathrm{k}_{0}$ is the additive constant, and $\mathrm{k}_{1}-\mathrm{k}_{36}$ are elements $1-36$, respectively. The additive constant is an expected value of the rating when elements 1-36 are all 0 . Each subject generates an individual additive constant. Beyond elements linear contribution to concepts the regression modeling may incorporate interactions as well. Also, data quality is assessed by computing the multiple $R^{2}$ statistics for the linear equation relating the presence/absence of concept elements to the scalar rating. 6) Any further rearrangements or analysis of the data to this point is subject to individual interests of the researcher, like; K-cluster analysis to form segmentations of the subject data, or simple ordering and/or ranking via SYSTAT13 and Microsoft Excel, respectively.

\section{Acknowledgments}

This work was supported by the USDA Florida Specialty Crops Block Grant. 


\section{References}

[1] S. Tulipani, B. Mezzetti and M. Battino, Impact of strawberries on human health: Insight into marginally discussed bioactive compounds for the Mediterranean diet, Public Health Nutr 12 (2009), 1656-1662.

[2] M. Battino, J. Beekwilder, B. Denoyes-Rothan, M. Laimer, G. McDougall and B. Mezzetti, Bioactive compounds in berries relevant to human health, Nutrition Reviews 67 (2011), 145-150.

[3] H.A. Ross, G.J. McDougall and D. Stewart, Antiproliferative activity is predominantly associated with ellagitannins in raspberry extracts, Phytochemistry 68 (2007), 218-228.

[4] Y. Zhang, N.P. Seeram, R. Lee, L. Feng and D. Heber, Isolation and identification of strawberry phenolics with antioxidant and human cancer cell antiproliferative properties, J Agr Food Chem 56 (2008), 670-675.

[5] J. Whitson, C.A. Hamilton, A. Crozier, E. Jardine, D. Stewart, G. McDougall, J.L. Reid and A.F. Dominiczak, Cardiovascularprotective properties of fruit and vegetable extracts. Abstracts of the Scottish Society for Experimental Medicine Meeting, Dundee, UK, $2004,18$.

[6] A. Basu, M. Wilkinson, K. Penugonda, B. Simmons, N.M. Betts and T.J. Lyons, Freeze-dried strawberry powder improves lipid profile and lipid peroxidation in women with metabolic syndrome: Baseline and post intervention effects, Nutr J 8 (2009), 7.

[7] G.J. McDougall, F. Shapiro, P. Dobson, P. Smith, A. Blake and D. Stewart, Different polyphenolic components of soft fruits inhibit a-amylase and a-glucosidase, J Agric Food Chem 53 (2005), 2760-2766.

[8] J.M. Alvarez-Suarez, D. Dekanski, S. Ristić, N.V. Radonjić, N.D. Petronijević, F. Giampieri, P. Astolfi, A.M. Gonzalez-Paramas, C. SantosBuelga, S. Tulipani, J. Quiles, B. Mezzetti and M. Battino, Strawberry polyphenols attenuate ethanol-induced gastric lesions in rats by activation of antioxidant enzymes and attenuation of mda increase, PLoS ONE 6(10) (2011), e25878, doi:10.1371/journal.pone.0025878.

[9] Y. Qin, J.A. Teixeira da Silva, L. Zhang and S. Zhang, Transgenic strawberry: State of the art for improved traits, Biotechnol Adv 26 (2008), 219-232.

[10] V.B. Duffy, Variation in oral sensation: Implications for diet and health, Current Opinion in Gastroenterology 23 (2007), $171-177$.

[11] D. Ulrich, Flavours of strawberry - diversity and creativity of nature, Mitt Klosterneuburg 60 (2010), $452-457$.

[12] V.M. Whitaker, Applications of molecular markers in strawberry, Journal of Berry Research 1(3) (2011), 115-127.

[13] K. Olbricht, D. Ulrich, K. Weiss and C. Grafe, Variation in the amounts of selected volatiles in a model population of Fragaria $\times$ ananassa Duch as influenced by harvest year, J Agr Food Chem 59 (2011), 944-952.

[14] D.W. Stewart, P.N. Shamdasani and D.W. Rook, Focus groups: Theory and practice. 2nd ed. Thousand Oaks: Sage Publications Inc., 2007.

[15] T. Gilovich, D. Griffin and D. Kahneman, Heuristics of Intuitive Judgment: Extensions and Applications, Cambridge University Press, New York, 2002.

[16] H. Moskowitz and A. Gofman, Selling blue elephants: How to make great products before people even know they want them, Wharton School Publishing, Philadelphia, PA, 2007.

[17] H.R. Moskowitz, Customer driven development: A paradigm for sustainable innovation in "cyberspace" using quantitative research methods, Aust J Market Res 9 (2001), 15-26.

[18] H.R. Moskowitz, A. Gofman, J. Beckley and H. Ashman, Founding a new science: Mind genomics, Journal of Sensory Studies 21 (2006), 266-307.

[19] H. Moskowitz, M. Reisner, B.J. Lawlor and R. Deliza Package research in food product design and development, Wiley-Blackwell, Indianapolis, IL, 2009.

[20] J.B. MacQueen, Some Methods for classification and Analysis of Multivariate Observations. Proc. of 5th Berkeley Symposium on Mathematical Statistics and Probability, University of California Press, (1967), p. 281-297.

[21] C. Jouquand, C. Chandler, A. Plotto and K. Goodner, A sensory and chemical analysis of fresh strawberries over harvest dates and seasons reveals factors that affect eating quality, J Amer Hort Sci 133(6) (2008), 859-867.

[22] P. Green and A.M. Krieger, Segmenting markets with conjoint analysis, Journal of Marketing 55 (1991), 20-31.

[23] N. Anderson, Functional measurement and psychological judgment, Psychological Review 77 (1970), 153-170.

[24] R.L. Plackett and J.P. Burman, The design of optimum multifactorial experiments, Biometrika 33(4) (1946), 305-325. 